Financial Statistical Journal (2018) Volume 1

doi:10.24294/fsj.v1i4.803

\title{
How Household Healthcare Expenditures Redistribute Disposable Income? An Analysis Using Bangladesh Household Income and Expenditure Survey, 2010
}

\author{
Azaher Molla $^{1^{*}}$, Chunhuei Chi \\ ${ }^{1}$ Department of Applied Health Sciences, Murray State University, Murray KY, 42071, USA \\ ${ }^{2}$ School of Biological and Population Health Sciences, Oregon State University, Corvallis OR 97331-5109, USA \\ ${ }^{*}$ Corresponding author: Address: 1628 Main St. Apt. 7, Murray, KY 42071, USA; email: amolla@murraystate.edu
}

\begin{abstract}
Essential healthcare is a civil right. Payments toward healthcare is a moral compulsion, and no less strong than legal compulsion like income tax. Healthcare payments can redistribute disposable income. Redistribution may be vertical (from rich to poor or opposite) and horizontal (from men to women or from households without children to households with children). Health planners are interested in degrees to which redistribution occurs. In this paper, we aim to analyze how well different forms of healthcare payments in Bangladesh redistribute disposable income. Our data comes from Bangladesh Household Income and Expenditure Survey, 2010. Using the methods developed by Aronson et al. (1994), we assessed average rate effect, progressivity, horizontal equity and re-ranking. The results suggest that Bangladesh health systems finance has a pro-rich redistribution of disposable income. Post-payment disposable income decreases for the poor and increases for the rich. As a result, the poor are in a shortfall in disposable income, which ultimately get them to impoverishment, and or push them to deeper poverty. On the contrary, the rich become richer due to increase in post-payment disposable income. This leads to an increase in inequality.
\end{abstract}

Keywords: Distribution of Disposable Income; Healthcare Payments; Bangladesh; Health Systems Finance; Inequity

\section{Introduction}

Financial protection for households and individuals is one of the main objectives of health systems finance. The amount of money that households have for spending and savings after deduction of income tax is known as disposable income. Redistribution of disposal income is an economic issue in general, and health economics issue in particular. Redistribution of disposable income may be intended or unintended. Policy makers and planners are interested in degrees to which redistribution occurs because of consequences for the distribution of goods and services other than healthcare. In general, distribution occurs when payments toward financing of healthcare are compulsory and independent of utilization. For example, under the United Kingdom's National Health Services (NHS), the better-off pays more for their healthcare than the worse-off. Protection against out-of-pocket (OOP) payments can be provided through taxation, social insurance, and private insurance. However, for the latter, risk-rate insurance premium does not provide such protection, as premium does consider the ability to pay (ATP). In addition, when healthcare payments are made voluntarily, they do not have a redistributive effect on economic welfare. The question arises here, whether the healthcare payments are made voluntarily or involuntarily. Any payment made voluntarily does not have a redistributive effect on economic welfare. But, healthcare payments are considered involuntary as it is a moral compulsion to purchase vital healthcare for self or for a relative. This moral compulsion is no less strong than the legal compulsion to pay income taxes. However, in most instances, there is discretion in the purchase of healthcare in response for a health problem.

Redistribution can be vertical and horizontal. The former may be progressive - from rich to poor, or regressive from poor to rich. In horizontal redistribution, distribution occurs from one kind of group to others, for example, from

Copyright (C) 2018 Azaher Molla et al.

doi: $10.24294 /$ fsj.v1i4.803

EnPress Publisher LLC.This work is licensed under the Creative Commons Attribution-NonCommercial 4.0 International License (CC BY-NC 4.0).

http://creativecommons.org/licenses/ by/4.0/ 
men to women, households without children to families with children. Vertical redistribution occurs when payments are disproportionately related to ATP. In case of horizontal redistribution, families with equal ATP contribute unequally to healthcare payments. The redistributive effect of a particular healthcare financing system depends not only on its progressivity, but also on the extent of vertical, horizontal, and re-ranking effects. Depending on the extent of horizontal inequity and re-ranking involved in healthcare finance, a progressivity analysis can give a misleading impression about the income redistribution associated with the financing system.

Our aim in this paper is to explore empirically the impact of healthcare payments on the distribution of disposable income. The analysis will answer the questions on how well different forms of health finance perform in terms of income protection. Following an overview of health systems finance in Bangladesh, we show and discuss the redistributive impacts and its constituents including average rate effect, progressivity, horizontal equity, and re-ranking.

\section{Health systems finance in Bangladesh}

Bangladesh has been suffering from excessively high burden of OOP health expenditure with an increasing trend, from 57 percent in 1997 to 63 percent in 2012 (BNHA, 2012). OOP as a percentage of private expenditure on healthcare is higher ( 92.9 percent) than India (82.2 percent), and Nepal (79.9 percent). OOP payments constitute 63 percent of the health system finance, and remain the main source of financing. Government tax revenue is the second largest financing agent comprising of 26 percent of total health expenditure (THE). Private firms and NGOs contribute 1-2 percent of the THE over the 1997 to 2012 period. Development partners' contribution varies from 5-9 percent during the period. Household expenditure as a percentage of gross domestic product (GDP) has increased from 1.6 percent to around 20 percent in 2010 (Adam et al., 2013).

Health spending in Bangladesh accounted for 3.4 percent of GDP, which is lower than the average (3.8 percent) in South East Asia (SEA) region, below the average of low-income countries and lower-middle income countries (4.3percent), and far below the world (8.5 percent) (Majumder, 2011). A breakdown of OOP expenditure shows that drugs and medicine contribute 65 percent, curative care 22 percent, ancillary services 9 percent, out-patient and home-based services 4 percent, and general government administration 1 percent (BNHA, 2012).

\section{Decomposing distributive effect}

The distribution impact is defined as the reduction in Gini coefficient caused by the healthcare payment. Thus, the redistribution may be measured by comparing inequality in prepayment income or Gini coefficient with inequality in post payment income or Gini coefficient (Lambert, 1989).

$$
\mathrm{RE}=\mathrm{G}^{\mathrm{x}}-\mathrm{G}^{\mathrm{x}-\mathrm{p}}
$$

Where, $G^{x}$ and $G^{x-p}$ are the prepayment and post payment Gini coefficient, respectively. Here, $x$ denotes the prepayment income or, more generally, some measures of ATP; and p denotes the payment. According to Aronson, Johnson, and Lambert (1994), this difference can be written as,

$$
\mathrm{RE}=\mathrm{V}-\mathrm{H}-\mathrm{R}
$$

Where, $\mathrm{V}$ is vertical redistribution, $\mathrm{H}$ is horizontal inequity, and $\mathrm{R}$ is the degree of re-ranking.

As there are few households in any sample with exactly the same prepayment income, researchers need to create artificial groups of prepayment equals within the prepayment income. The vertical redistribution component can be defined as,

$$
V=G^{x}-G^{0}
$$

Where, $G^{0}$ is the between groups Gini coefficient for post payment income. This equation (3) can be computed by replacing all post payment incomes with their group means. Then $\mathrm{V}$ can be decomposed into prepayment rate effect and a progressivity effect.

$$
\mathrm{V}=\left[\frac{\mathrm{g}}{1-\mathrm{g}}\right] \mathrm{K}_{\mathrm{E}}
$$

Where $g$ is the sample average prepayment rate, and $\mathrm{K}_{\mathrm{E}}$ is the prepayment Kakwani index (Kakwani, 1977) that would arise if there were horizontal equity in healthcare payments. It is computed as the difference between the between-groups concentration index for prepayment and $G^{x}$. 
Horizontal equity $(\mathrm{H})$ is measured by the weighted sum of the product of post payment income share and post payment Gini coefficient.

$$
\mathrm{H}=\sum \alpha_{\mathrm{j}} \mathrm{G}_{\mathrm{j}}^{\mathrm{x}-\mathrm{p}}
$$

Where, $\alpha_{j}$ is the group specific post payment income, and $G_{i}^{x-p}$ is the group specific post payment Gini coefficient. As the Gini coefficient for each group of payment equals is non negative, the horizontal inequity is also negative. $\mathrm{Hcan}$ only reduce redistribution and never can increase it. It means that $\mathrm{H}$ will always make a post payment distribution of incomes more unequal than it would have been in its absence.

Lastly, $R$ captures the extent of re-ranking of households that occurs due move from prepayment to the post payment distribution of income, and can be written as

$$
\mathrm{R}=\mathrm{G}^{\mathrm{x}-\mathrm{p}}-\mathrm{C}^{\mathrm{x}-\mathrm{p}}
$$

Where, $\quad \mathrm{C}^{\mathrm{x}-\mathrm{p}}$ is the post payment income concentration index. The latter is obtained by first ranking households by their prepayment incomes and then within each group of payment "equals," by their post payment income. $R$ is always positive, because the concentration curve of post payment income cannot lie below the Lorenz curve of post payment income. When both the curves coincide, the two indexes are equal and no re-ranking occurs.

In conclusion, the total redistribution effect is decomposed into four components: an average rate effect ( $\mathrm{g}$ ), the departure from proportionality or progressivity effect $\left(\mathrm{K}_{\mathrm{E}}\right)$, a horizontal inequity effect $(\mathrm{H})$, and a re-ranking effect $(\mathrm{R})$. It is of great importance to note that an arbitrary choice of income interval is required for its practical execution. However, choice will not affect the total $H+R$. In general, the larger the income intervals, the greater the estimates of horizontal inequity and the smaller the estimation of re-ranking (Aronson, Johnson, and Lambert 1994).

\section{Data and Methods}

We have employed the method of Aronson et al. (1994) to decompose the effect of Bangladesh healthcare financing system into three components: a progressivity component, a classical horizontal equity component, and a re-ranking component.

This study uses Bangladesh Household Income and Expenditure Survey (HIES) 2010 dataset conducted by Bangladesh Bureau of Statistics (BBS, 2011). This is the source of data for estimating household income, expenditure, consumption, income inequality and incidence of poverty. This is a cross sectional and nationally representative sample of 12,240 households. HIES is being conducted for every five years and HIES 2010 is the $15^{\text {th }}$ round of survey. The survey captured the seasonal variations. For this round data collection was started on $1^{\text {st }}$ February 2010 and continued up to $31^{\text {st }}$ January 2011. The entire period of one year has been divided into 18 terms. In each term, a total of 34 primary sampling units (PSUs) were covered to collect data from all 680 sample households.

\section{Survey design}

A two-stage stratified random sampling technique was followed in drawing sample for this survey under the framework of Integrated Multipurpose Sampling (IMPS) design developed on the basis of Bangladesh population and housing census, 2001. In IMPS design, the whole country was divided into 16 strata, which included six from rural, six from urban, and four from sub-municipal areas (SMAs). The design consists of 1000 PSUs throughout the country systematically drawn from the 16 strata. Of 1000 PSUs, 640 were from the rural and 360 were from the urban areas. Each PSU comprises around 200 households. In the first stage, out of 1000, 612 PSUs were drawn. In the second stage, 20 households were randomly selected from each PSU. Thus, PSUs selected for HIES 2010 are actually a subset of PSUs of the IMPS design. The total sample size stands at 12,240 households consisting of a population of 55,580. Table 1 depicts the sampling summary.

\section{Findings}

The average financing budget share, or payments as fraction of income indicates that OOP health expenditure is the largest source of financing and represents, on average, 4.2 percent of household budget. With 0.3 percent household yearly tax is the second largest financing source. Social insurance contributes a minimum of 0.2 percent, whereas, 
private insurance contributes nearly nothing. There is a big discrepancy between the lowest quintile and the highest quintile. The poor pay 6.2 percent of their total consumption for healthcare, whereas, the rich pay 2.6 percent for the healthcare consumption. Similar findings are observed in case of tax and social insurance. However, in case of private insurance both the worse-off and better-off pay nearly nothing. Concentration indexes are positive for tax, social insurance and household OOP. However, for social insurance confidence interval contains zero $(0.1040 \pm 0.07)$. Gini coefficient increases from prepayment to post payment ( 0.3134 vs 0.3276$)$. It means that the income inequality increases after incurring healthcare expenditure. Kakwani indexes are negative for all financing sources indication that the worse-off bears the burden. In the absence of horizontal inequity, all the financing sources would be regressive (Table 2).

\begin{tabular}{|l|l|l|l|}
\hline Items & Total & Rural & Urban \\
\hline Number of PSUs & $612(100 \%)$ & $392(64 \%)$ & $220(36 \%)$ \\
\hline Number of households & $12,240(100 \%)$ & $7,840(64 \%)$ & $4,400(36 \%)$ \\
\hline Number of population & $55,580(100 \%)$ & $35,894(64.58 \%)$ & $19,686(35.42 \%)$ \\
\hline
\end{tabular}

Table1. A summary of the sample coverage, Bangladesh HIES, 2010

\begin{tabular}{|c|c|c|c|c|c|c|c|}
\hline & $\begin{array}{l}\text { Per capita } \\
\text { consumption, gross }\end{array}$ & $\begin{array}{l}\text { Household } \\
\text { yearly tax } \\
\text { in BDTk. }\end{array}$ & $\begin{array}{l}\text { Household } \\
\text { yearly } \\
\text { social } \\
\text { health } \\
\text { insurance } \\
\text { in BDTk. } \\
\end{array}$ & $\begin{array}{l}\text { Household } \\
\text { yearly } \\
\text { private } \\
\text { health } \\
\text { insurance } \\
\text { in BDTk. } \\
\end{array}$ & $\begin{array}{l}\text { Household } \\
\text { yearly } \\
\text { out-of-pocket } \\
\text { health } \\
\text { expenditure } \\
\text { in BDTk. }\end{array}$ & $\begin{array}{l}\text { Total } \\
\text { payments }\end{array}$ & $\begin{array}{l}\text { Per capita } \\
\text { consumption, } \\
\text { net of } \\
\text { payments }\end{array}$ \\
\hline \multicolumn{8}{|l|}{$\begin{array}{l}\text { Quintiles of per capita } \\
\text { consumption, gross }\end{array}$} \\
\hline Lowest quintile & 100.0 & 0.4 & 0.3 & 0.0 & 6.2 & 6.8 & 93.4 \\
\hline standard error & 0.00 & 0.07 & 0.07 & 0.00 & 0.32 & 0.34 & 0.29 \\
\hline 2 & 100.0 & 0.4 & 0.2 & 0.0 & 5.8 & 6.4 & 94.0 \\
\hline standard error & 0.00 & 0.08 & 0.04 & 0.01 & 0.47 & 0.48 & 0.28 \\
\hline 3 & 100.0 & 0.4 & 0.2 & 0.0 & 5.7 & 6.4 & 94.5 \\
\hline standard error & 0.00 & 0.06 & 0.07 & 0.02 & 0.71 & 0.72 & 0.24 \\
\hline 4 & 100.0 & 0.3 & 0.2 & 0.0 & 4.2 & 4.7 & 95.5 \\
\hline standard error & 0.00 & 0.06 & 0.06 & 0.00 & 0.30 & 0.31 & 0.20 \\
\hline Highest quintile & 100.0 & 0.3 & 0.1 & 0.0 & 2.6 & 3.0 & 97.1 \\
\hline standard error & 0.00 & 0.06 & 0.04 & 0.00 & 0.14 & 0.16 & 0.12 \\
\hline Total & 100.0 & 0.3 & 0.2 & 0.0 & 4.2 & 4.7 & 95.6 \\
\hline standard error & 0.00 & 0.03 & 0.02 & 0.00 & 0.16 & 0.17 & 0.09 \\
\hline Gini coefficient & 0.3134 & & & & & & 0.3276 \\
\hline standard error & 0.00 & & & & & & 0.00 \\
\hline Concentration Index & & 0.2419 & 0.1040 & -0.1208 & 0.1128 & 0.1217 & \\
\hline standard error & & 0.05 & 0.07 & 0.06 & 0.02 & 0.02 & \\
\hline Kakwani index & & -0.0714 & -0.2094 & -0.4342 & -0.2005 & -0.1917 & \\
\hline standard error & & 0.05 & 0.07 & 0.06 & 0.02 & 0.02 & \\
\hline
\end{tabular}

Table 2. Financing budget shares, Bangladesh 2010 
The poorest quintile consumes, on average, 9 percent of total consumption, whereas the richest quintile consumes 41 percent. Taxes appear to be borne by the upper three quintiles, 17.7, 20.9 and 37.4 percent. The lowest two quintiles consume 9.0 and 14.6 percent. The financing share increases by quintile for taxes. In case of social health insurance fourth quintile consumes the most ( 25.5 percent) followed by the highest quintile ( 23.7 percent). The lowest and the second quintile consumes nearly the same percent for social insurance (14.7 and 14.8 percent). In both per capita gross consumption and household yearly tax, the richest quintile bears the greater share, 40.9 and 37.4 percent respectively, which are 3.94 and 4.5 times higher than the lowest quintile. In respect of social health insurance, the poorest quintile bears 15 percent share, whereas the richest quintile bears 24 percent. Although, private insurance is either absent, or if present only in some pocket areas. The figures are surprising; the middle class or third quintile bears the highest share (79 percent). Whereas, the poorest and the fourth quintiles bear nothing and the richest quintile bear only 2.8 percent share

In the absence of horizontal inequity, social insurance, private insurance, and OOP payments would have Kakwani indexes $-0.2052,-0.5118$, and -0.2033 respectively. All these indicate regressivity of financing. Household yearly tax is also regressive, but less so $(-0.0644)$. The total redistributive effect of household tax, social insurance and OOP payments are all negative, and show an increase in income inequality. For private insurance, the impact is zero.

When decomposing the total distribution effect, the increase in income inequality due to household tax, social insurance, and OOP payments are mostly horizontal as the ratio V/RE is farther to $1(-0.0008,-0.0007$, and -0.0100 respectively). Inequality is thus increases because the rich pay less to their income. The negative redistributive effect or increase in income inequality caused by household OOP health expenditure at 89.00 percent is due to a negative vertical effect $(\mathrm{V} / \mathrm{RE}=0.8900)$ and 11 percent is due to horizontal inequity. It is more surprising to note that $\mathrm{V} / \mathrm{RE}$ is much farther from 100 percent in case of household tax $(0.2625)$ and social health insurance $(0.4679)$. These indicate that for these sources there is considerable variation in the amount paid at a given level of income (Table 3).

Finally, since total redistributive effect (RE) and vertical effect (V) have opposite signs for household tax, social insurance and OOP payments, it is not possible to interpret the relative measures of the decomposition. The analysis of the corresponding absolute values shows that this financing has strong horizontal inequity and positive vertical effect. This means that the rich contribute proportionally less than the poor, despite their greater healthcare utilization. Indeed, the strong horizontal inequity observed is likely to come from the health heterogeneity in the population. 


\begin{tabular}{|c|c|c|c|c|c|c|}
\hline & $\begin{array}{l}\text { Per capita } \\
\text { consumption, } \\
\text { gross }\end{array}$ & $\begin{array}{l}\text { Household } \\
\text { yearly tax } \\
\text { in BDTk. }\end{array}$ & $\begin{array}{l}\text { Household } \\
\text { yearly } \\
\text { social } \\
\text { health } \\
\text { insurance } \\
\text { in BDTk. } \\
\end{array}$ & $\begin{array}{l}\text { Household } \\
\text { yearly } \\
\text { private } \\
\text { health } \\
\text { insurance } \\
\text { in BDTk. }\end{array}$ & $\begin{array}{l}\text { Household } \\
\text { yearly } \\
\text { out-of-pocket } \\
\text { health } \\
\text { expenditure } \\
\text { in BDTk. }\end{array}$ & $\begin{array}{l}\text { Total } \\
\text { payments }\end{array}$ \\
\hline \multicolumn{7}{|l|}{ Quintiles of per capita consumption, gross } \\
\hline Lowest quintile & 9.0 & 9.5 & 14.8 & 0.0 & 13.4 & 13.2 \\
\hline 2 & 12.8 & 14.6 & 14.7 & 17.8 & 17.8 & 17.5 \\
\hline 3 & 16.1 & 17.7 & 21.3 & 79.4 & 22.0 & 21.8 \\
\hline 4 & 21.2 & 20.9 & 25.5 & 0.0 & 21.3 & 21.4 \\
\hline Highest quintile & 40.9 & 37.4 & 23.7 & 2.8 & 25.5 & 26.2 \\
\hline Total & 100.0 & 100.0 & 100.0 & 100.0 & 100.0 & 100.0 \\
\hline Payments as fraction of Income (g) & 1.0000 & 0.0034 & 0.0016 & 0.0001 & 0.0418 & 0.0470 \\
\hline $\begin{array}{l}\text { Kakwani index assuming horizontal } \\
\text { equity }(\mathrm{Ke})\end{array}$ & 0.0000 & -0.0644 & -0.2052 & -0.5118 & -0.2033 & -0.1936 \\
\hline Vertical effect (V) & 0.3077 & -0.0002 & -0.0003 & 0.0000 & -0.0089 & -0.0095 \\
\hline Horizontal inequality $(\mathrm{H})$ & -0.0056 & 0.0003 & 0.0002 & 0.0000 & 0.0027 & 0.0032 \\
\hline Reranking (R) & 0.0000 & 0.0004 & 0.0002 & 0.0000 & -0.0016 & -0.0010 \\
\hline $\begin{array}{l}\text { Total redistributive effect }(\mathrm{RE}=\mathrm{V}-\mathrm{H}- \\
\mathrm{R})\end{array}$ & 0.3134 & -0.0008 & -0.0007 & 0.0000 & -0.0100 & -0.0117 \\
\hline $\mathrm{V} / \mathrm{RE}$ & 0.9821 & 0.2625 & 0.4679 & 0.6908 & 0.8900 & 0.8157 \\
\hline $\mathrm{H} / \mathrm{RE}$ & -0.0179 & -0.3031 & -0.2200 & -0.1121 & -0.2674 & -0.2707 \\
\hline $\mathrm{R} / \mathrm{RE}$ & 0.0000 & -0.4344 & -0.3121 & -0.1971 & 0.1574 & 0.0864 \\
\hline
\end{tabular}

Table 3. Decomposition of redistributive impact of health care financing system, Bangladesh 2010

\section{Discussion}

Decomposition of redistributive effects analysis shows that in absence of horizontal inequity, Kakwani indexes are negative, which indicates regressivity. The total redistributive effects of household tax, social insurance and OOP payments are negative, which show an increase in income inequality. It indicates that after household healthcare payments, the poor face a negative impact in disposable income. Whereas, after paying the healthcare expenditure the rich have a proportional increase in disposable income.

When decomposing the total distribution effect, the increase in income inequality for household tax, social insurance and OOP payments are mostly horizontal. Inequality increases, because the rich pays proportionately less to their income. For the OOP payments, 89 percent is for vertical effect and 11 percent is for horizontal inequity. Besides decomposition, it may be concluded from the analysis that the rich contribute proportionally less than the poor, despite their greater healthcare utilization. The strong horizontal inequity may be explained by the fact that they come from the health heterogeneity in the population.

In Bangladesh, like other low-income countries, OOP payments contribute the greatest share of revenue (63.3 percent). The Lorenz dominance analysis indicates that the inequality exists in all sources of healthcare finance. The graphs offer a powerful means of representing the effect of healthcare financing on the distribution of household living standards. It should be borne in mind that this kind of analysis does not consider utilization of healthcare. Progressivity 
should not be interpreted as the rich paying more for the same amount of healthcare, as this is most often not the case and not accounted for the measure presented here.

\section{Conclusion}

Our findings substantially add to the evidence base on the redistribution of disposable income as a consequences of household healthcare payments. The latter decreases the disposable income of the poor. Our results suggest that Bangladesh healthcare financing system has a pro-rich redistribution effect. Most of this is due to the system regressiveness. Post payment disposable income decreases for the poor, and increases for the rich. This cause a double burden for the worse-off. Being poor they cannot meet their required nutrition, and suffer from more diseases and health conditions. After payment for healthcare, they are in a shortfall in disposable income, and suffer more from diseases and health conditions, which ultimately get them to impoverishment and, or push them to a deeper poverty. On the contrary, the rich become richer. The inequality between them increases. The policy makers and planners need to devise alternative financing system including innovative risk pooling, so that the financing may turn to a progressive system, and the income redistribution will in favor of the poor. This will ultimately add up to more social capital, economic development and fairness in healthcare financing.

Despite the fact that household income and expenditure survey is the ideal source of data for this kind of analysis, the study has some limitations. As usual, survey data are potentially subject to recall bias. The conventional analysis provides no information on households who cannot afford to use health services and not incurred any expenses. The present study does not assess the obvious impact of OOP payments on the quantity and quality of care consumed.

Further research on routine follow ups on this issue is highly warranted. Development of country specific alternative healthcare financing strategies are of great importance to protect the poor and vulnerable from financial catastrophe and impoverishment. Disaggregated research findings by divisions and district may unveil the secrecy of horizontal inequity.

\section{Authors Contributions}

AAM participated in the research design, data compilation, analysis and writing the original text. CC in finalization of research design, analysis and edited the final manuscript. Both the authors read and approve the final manuscript.

\section{Conflict of Interest}

The authors declare that they have no competing interests.

\section{Acknowledgements}

We are thankful to Bangladesh Bureau of Statistics for providing us the dataset on Household Income and Expenditure Survey, 2010. We are deeply thankful to the anonymous reviewers of the journal.

\section{References}

1. Aronson JR, Johnson P, \&amp; Lambert PJ. Redistributive Effect and Unequal Tax Treatment. Economic Journal 1994; 104(423): 262-70.

2. Bangladesh Bureau of Statistics, 2011. Report of the Household Income and Expenditure Survey, 2010. Ministry of Planning. Government of the People's Republic of Bangladesh. Dhaka, Bangladesh.

3. Bangladesh National Health Account (BNHA) 2007-2012. Health Economics Unit (HEU), Ministry of Health and Family Welfare. Government of the People's Republic of Bangladesh. Dhaka.

4. Adams AM, Ahmed T, El Arifeen S, et al. Innovation for universal health coverage in Bangladesh: a call to action. The Lancet. 2013 Dec 21; 382(9910):2104-11.

5. Kakwani NC. Measurement of tax progressivity: an international comparison. The Economic Journal. 1977 Mar 1; 87(345):71-80.

6. Lambert PJ. The distribution and redistribution of income. In Current issues in public sector economics 1992 (pp. 200-226). Palgrave, London.

7. Majumder MA. World Health Statistics 2011: How does Bangladesh compare with other South-East Asian countries? South East Asia Journal of Public Health. 2013 Jan 8;1(1):4-11. 